\title{
Problemas y retos de futuro de la genética forense en el siglo XXI
}

\section{Problems and future challenges of forensic genetics in the XXI century}

\section{Resumen}

Desde que en 1985 Alec Jeffreys introdujo la huella genética ha habido una evolución continua en el tipo de marcadores y en las tecnologías utilizadas en genética forense. Los microsatélites en cromosomas autonómicos son actualmente los marcadores más utilizados, junto con polimorfismos en cromosomas sexuales y el ADN mitocondrial, pero los polimorfismos nucleotídicos simples (SNPs) van emergiendo como marcadores de futuro y son ya útiles para muchas aplicaciones específicas, lo que, junto con nuevas técnicas de ultrasecuenciación de genomas, abre nuevas posibilidades no soñadas hace unos años.

Con todo, los retos prioritarios de la genética forense no son esencialmente tecnológicos: la valoración estadística de la prueba del ADN en los casos complejos (particularmente en mezclas o muestras de contacto), la comunicación del valor de la prueba, el control de calidad, el futuro de la I+D, la formación, los estándares éticos, entre otros, son problemas a los que nos tenemos que enfrentar con urgencia.

Palabras clave: Genética forense. ADN. Prueba pericial. Problemas. Retos.

\section{Abstract}

Since the discovery of polymorphisms in repetitive DNA by Alec Jeffreys and coworkers in 1985 the type of biomarkers and technologies used in forensic genetics has experienced a continuous evolution. Microsatellites in autosomal chromosomes known as STRs and polymorphism in the sexual chromosome and mitochondrial DNA are the most commonly used but new markers are arising and SNPs together with the new sequencing technologies are open new possibilities and a range a new applications.

Nevertheless the challenges in the field are not technological: the statistical evaluation of DNA testing, the communication of the weight of the evidence and the correct understanding of this value, educational and ethical issues or the future of R\&D are problems that should be urgently faced.

Key words: Forensic genetics. DNA. Expert witness testimony. Problems. Challenges.

\section{Genética forense}

La genética forense es una subespecialidad de la Genética y de la Medicina Legal que incluye un conjunto de conocimientos de genética necesarios para resolver ciertos problemas judiciales. Los tipos de pericia más solicitados al laboratorio de genética forense por los tribunales son casos de investigación biológica de la paternidad, pericias de criminalística biológica (estudio de vestigios biológicos de interés criminal como manchas de sangre, esperma, pelos, muestras de contacto, etc.) y, finalmente, problemas de identificación. Una de las actividades más importantes del campo son las bases de datos de ADN con fines de identificación criminal. La primera base de datos fue la del Reino Unido. Es muy amplia y contiene unos tres millones de perfiles de ADN, introduciéndose más de 1000 perfiles diarios de

\section{A. Carracedo \\ A. Salas \\ MV. Lareu}

Instituto Universitario de Medicina Legal, Universidad de Santiago de Compostela.

Correspondencia: Dr. Ángel Carracedo. Instituto Universitario de Medicina Legal. Facultad de Medicina. C/ San Francisco s/n. 15782 Santiago de Compostela E-mail: angel.carracedo@usc.es

Fecha de recepción: 28.MAR.2010

Fecha de aceptación: 8.ABR.2010 
sospechosos, convictos o muestras encontradas en el lugar de los delitos. Actualmente existen bases de datos en prácticamente la totalidad de los países europeos.

Es de todos conocido que hubo un antes y después en genética forense desde que fueron descubiertas, por Alec Jefffreys y colaboradores en $1985^{1}$, regiones muy polimórficas en el ADN no codificante, y que desde entonces ha habido una evolución continua de marcadores genéticos y tecnologías ${ }^{2}$.

Actualmente los miscrosatélites (STRs, short tandem repeats) son los marcadores base de la genética forense, han sido muy estandarizados, de modo que sólo se emplean unos pocos en forma de kits comerciales muy eficaces, lo que facilita la comparación de resultados. Con todo, no existe una postura estática sobre los microsatélites, y en Europa se han diseñado estrategias de substitución paulatina de microsatélites poco eficaces por otros con mayor rendimiento ${ }^{3}$. Para muestras parcialmente degradadas se han introducido los miniSTR ${ }^{4}$ que, gracias a la reducción del tamaño del producto amplificado, poseen mayor utilidad en la práctica forense en este tipo de material.

Se han estandarizado y validado numerosos microsatélites de cromosoma $Y$ y existen kits comerciales eficaces y optimizados para su determinación y, finalmente, el análisis por secuenciación del D-loop mitocondrial es una técnica de rutina para el análisis de pelos o casos de identificación en muestras degradadas, y al igual que para cromosoma $Y^{5}$ existen bases de datos poblacionales de calidad que permiten hacer cálculos estadísticos en este tipo de marcadores ${ }^{6}$.

\section{El futuro tecnológico}

La pregunta es entonces, ¿necesitamos realmente nuevos marcadores?

La respuesta es que sí, sin duda alguna. Y no sólo porque hay casos que no se solucionan con técnicas convencionales y en los que la degradación (especialmente en casos de cantidad mínima de ADN) sigue siendo un problema, sino porque sería un absurdo no beneficiarnos del progreso de la genómica para fines de investigación policial o judicial.

Entre los nuevos marcadores, sin duda, son los polimorfismos simples de un solo nucleótido (SNPs, single nucleotide polymorphisms) los más prometedores.

Existen ya actualmente multiplexes de SNPs validados para uso forense ${ }^{7}$ que están permitiendo solucionar muchos casos complicados de paternidad ${ }^{8} \mathrm{y}$ especialmente de criminalística e identificación ${ }^{9}$.
SNPs de cromosoma $Y^{10}$ y especialmente de ADN mitocondrial ${ }^{11}$ están permitiendo un aumento de la información que se puede obtener del análisis de los linajes paterno y matero respectivamente, pero, además, el análisis de SNPs está permitiendo trazar el origen geográfico de la persona de la que proviene una muestra biológica ${ }^{12}$ e incluso obtener datos de rasgos físicos ${ }^{13}$ a partir de la misma.

Estas dos últimas aplicaciones tienen como objeto la investigación policial y no el uso judicial de la prueba y están facilitando la investigación criminal.

El futuro ya está sin duda en secuenciación a gran escala de cromosomas enteros o de todo el genoma ${ }^{14}$, incluso a partir de una molécula simple ${ }^{15}$. El abaratamiento de las técnicas de ultrasecuenciación y su diseño bioquímico hace que sus potenciales aplicaciones forenses no sean ciencia ficción. El proyecto genoma humano costó más de 3,5 mil millones de euros, con miles de científicos y técnicos de muchos países y 13 años de trabajo; actualmente se puede secuenciar un genoma humano completo en pocos días por menos de 6.000 euros, y no es un sueño pensar que en muy poco tiempo costará menos de 1.000 .

\section{Límites y estándares éticos}

La investigación sobre genomas completos, e incluso características físicas, y sobre marcadores de ancestralidad para predecir origen geográfico no están exentas de una polémica ética, a nuestro modo de ver muy mal enfocada, como ocurre tantas veces en genética forense.

No vemos que exista nada éticamente criticable en esta determinación como, a fin de cuentas, no existe nada malo en que un testigo dé datos sobre si el individuo que cometió el crimen le parece europeo, asiático o africano, o sobre si es rubio o tiene los ojos azules.

Otra cosa muy distinta es que la investigación sobre genes que determinan rasgos físicos pudiese derivar en un mal uso de los mismos, con fines de selección eugenésica o de elección a la carta de un hijo, lo que no tiene nada que ver con la problemática forense. El peligro permanente de los avances científicos entre el fin legítimo y el uso inadecuado, es una constante que ha sucedido en toda la historia de la ciencia. El error, introducido en muchas legislaciones, de limitar el uso forense del ADN al ADN codificante es un ejemplo de mal enfoque ético que es extensivo a otras aplicaciones de la genética en Medicina. Primero porque el ADN no codificante tiene a veces 
funciones reguladoras importantes, como es el caso de varios microsatélites que se emplean en genética forense, $y$, al contrario, variaciones en ADN codificante a veces no tienen absolutamente ningún significado funcional ni puede obtenerse de ellas ninguna información relacionada con el individuo, como es el caso de la mayoría de los SNPs que usan en genética forense; pero es que, además, no hay nada de éticamente reprochable en el uso de información como la que hemos indicado anteriormente, referida a rasgos físicos u origen geográfico. Lo éticamente reprochable sería no usarla si la justicia se puede beneficiar de estos avances.

Con todo, hay problemas éticos importantes en el campo que exigen la rápida introducción de estándares éticos. El primero es el problema de si se debe requerir de forma obligatoria o no el consentimiento expreso de la madre en caso de pruebas de paternidad en menores con patria potestad compartida. Aunque existe un pronunciamiento en contra de la mayoría de los comités de bioética ${ }^{16}$ es una práctica habitual en la mayoría de los laboratorios privados españoles.

Del mismo modo es necesaria una reflexión sobre las distintas posturas legislativas en países europeos sobre bases de datos de ADN con fines de identificación criminal (el legislador español le ha dado el curioso nombre de bases de datos de identificadores). La tendencia a hacerlas cada vez más amplias y extenderlas, como ocurre en algún país, a menores, a individuos absueltos o a mantener perfiles de ADN después del fallecimiento, no puede menos de llevarnos a reflexionar si, en ese equilibrio difícil entre seguridad y libertad, no estamos dando la libertad como garantizada y entrando en una pendiente deslizante que recuerda el mito de la caverna de Platón.

Un problema crucial: estadística e interpretación del valor de la prueba

Nuestra opinión compartida con muchos científicos líderes en este campo es que el avance más importante de la historia de las ciencias forenses ha sido la introducción de la valoración probabilística de la prueba. Ha representado el paso de una medicina forense artesanal, basada en modelos heurísticos, en la experiencia y en la que el perito da un valor no cuantificado y a menudo absoluto, cuando no puramente dogmático, a su opinión, a un modelo basado en la evidencia, como ha ocurrido en otras ramas de la Medicina, con una opinión basada en el conocimiento, en el entendimiento del proceso, en los datos y que permite valorar la incertidumbre de la opinión en términos científicos cuantificables.
Es un proceso que está permitiendo una distinción clara entre lo que es una prueba científica ("scientific evidence") o la simple opinión de un experto.

Con todo, no es fácil ni el cálculo de la probabilidad ni su comunicación ni la comprensión correcta por parte de jueces y jurados del significado de una probabilidad. Muy a menudo se suele confundir lo que le interesa al juez (probabilidad de que sea culpable contra probabilidad de que sea inocente) con el papel del experto (probabilidad de que la prueba de ADN haya dado ese resultado si el acusado es culpable respecto a si es inocente), y el no comprender bien esa diferencia y el rol específico de jueces y peritos es una de las causas de error más frecuentes en la comunicación.

Con todo, el cálculo estadístico del valor de las conclusiones del perito, tanto en pruebas de paternidad, en identificación como en criminalística biológica, ha mejorado de forma notable en los últimos años. Los peritos están cada vez mejor preparados y ha sido crucial la inclusión de la estadística en las pruebas de control de calidad, aunque sigue siendo notablemente más alto el porcentaje de errores estadísticos cometidos por los laboratorios que los errores técnicos.

El cálculo correcto de la probabilidad, su comunicación correcta y su entendimiento por los receptores de la pericia continúa siendo el gran reto de la genética forense a nivel práctico y también a nivel científico.

En este último sentido sigue siendo un problema el cálculo de la probabilidad en casos complejos, particularmente en mezclas de perfiles y en muestras con muy poco ADN y a menudo degradadas (Ilamado ADN de bajo número de copias, aunque este término se está abandonando porque debe exigir el mismo tratamiento que las mezclas complejas). Aunque existe una base teórica científica robusta sobre cómo abordar este tipo de casos, no hay programas validados apropiados para evaluarlos estadísticamente y hay una necesidad también de un esfuerzo formativo importante de los peritos para comprender las bases teóricas del procedimiento. Estas dificultades están originando no pocas controversias y la Comisión de ADN de la ISFG (Sociedad Internacional de Genética Forense) tiene necesidad de emitir pronto recomendaciones consensuadas al respecto, así como es necesario estimular a los fabricantes de software y hacer un trabajo experimental de validación.

\section{Los estándares y la calidad}

Hay que reconocer que donde sí que el progreso de la genética forense ha sido impresionante en estos 
años y que sólo después de mucho tiempo está empezando a seguir la genética clínica y otras ramas de la medicina forense, han sido los estándares. Y este progreso ha sido notable tanto en estándares técnicos como de procedimiento.

Los estándares técnicos incluyen el tipo de marcadores genéticos que deben de ser usados, su nomenclatura, la metodología válida para su análisis, los métodos estadísticos utilizados para la valoración de la prueba, la elaboración del informe final y su comunicación.

Las estándares de procedimiento incluyen todos aquellos necesarios para una acreditación de laboratorios e incluyen aspectos como la organización del laboratorio, el personal (su formación, entrenamiento específico, experiencia, responsabilidades, etc.), la documentación y el control de las pruebas, los protocolos de laboratorio, el calibrado y el mantenimiento de los equipos, los controles externos e internos, las auditorías externas y su frecuencia, etc.

La estandarización ya contemplada por el Consejo de Europa en su Recomendación R (92)1 de 10 de febrero de 1992 debe su éxito a la existencia de grupos nacionales y supranacionales (en Europa EDNAP y el grupos de trabajo de ADN de ENFSI), así como algunos grupos de trabajo de la ISFG (www.isfg.org) y, particularmente, al Grupo de Español y Portugués (GEP-ISFG), que es uno de los más activos y el que mejor sistema de pruebas de suficiencia posee a nivel mundial.

La DNA Commission de la ISFG vela por la armonización de los estándares a nivel mundial y emite de forma regular recomendaciones sobre aspectos de la pericia en genética forense que exigen claridad.

De todos modos, el éxito de los estándares en este campo no debe llevar a equiparar estándares a calidad. En este sentido es muy loable la recomendación (y para bases de datos de ADN la obligación en nuestro país) de acreditación de los laboratorios con normas ISO 17025, pero sería un grave error equiparar acreditación a calidad científica de un laboratorio, como a veces erróneamente se da entender, y es necesaria una armonización de los criterios de calidad entre las distintas agencias nacionales.

\section{Formación e investigación}

En el panorama organizativo en nuestro país, de total caos de la medicina forense -y la genética forense no es una excepción-, la coordinación y la formación cobran un papel clave.
Es un problema que no exista una formación reglada en genética forense, como no la hay en genética clínica, y que la entrada en los centros de trabajo se base en sistemas decimonónicos de oposición o en carreras académicas en las que promoción es básicamente por producción en investigación, pero que en las que no se exige un conocimiento básico de la especialidad.

Si esto se extiende a que es un problema general del mundo del derecho, donde la promoción por oposición pero no por un sistema reglado de formación es la regla, hace que la necesidad de un cambio en los procedimientos formativos sea aun más acuciante. La medicina legal, y con ella la genética forense, está curricularmente incluida en la licenciatura de Medicina (con un peso progresivamente menor) y sólo en unas pocas universidades en la licenciatura de derecho, donde debería ser una materia obligatoria, como lo debería ser en la formación específica de jueces y fiscales.

Es necesario a nivel europeo el diseño de un curriculum formativo en genética forense, y se están dando pasos ya en ese sentido aunque por las peculiaridades históricas de la medicina legal española resultará mucho más difícil su implantación en este país.

Ligado a este problema está la investigación. Una reciente editorial de Nature ${ }^{17}$ Ilamaba la atención de que la falta de vinculación de la academia a la práctica forense en muchos países estaba produciendo una catástrofe en la aplicación de la medicina legal a la justicia y que la inversión en investigación era muy insuficiente. $Y$ si esto es verdad a nivel norteamericano y en Europa, incluso en países con una tradición en medicina legal de mayor apoyo institucional, la situación aquí es dramática. El Ministerio de Justicia jamás ha invertido en I+D, al contrario que el Ministerio de Sanidad donde existe un fondo de investigación muy importante (Fondo de Investigación Sanitaria del Instituto de Salud Carlos III), y lo que es peor: en el último programa marco de la Unión Europea para investigación la medicina forense queda fuera de los programas Health y Security con lo que el panorama es desalentador. Sin $I+D$ no puede haber progreso y, en este caso concreto, como denuncia Nature, sus consecuencias son desastrosas para la Justicia.

\section{A modo de epílogo}

Quedan por debatir muchos aspectos relacionados con los modelos jurisprudenciales, con la introducción de los jurados y su efecto en la comunicación de 
la pericia, la relación de los peritos y los jueces y su rol, entre otros muchos temas que no son exclusivos de la genética forense sino de la medicina forense en general, aunque sí deben ser objeto de debate y reflexión.

La genética forense es una de las especialidades más apasionantes de la medicina legal debido al vértigo de los avances y descubrimientos en genómica y ayuda cada vez más a la investigación policial y a la justicia.

\section{Bibliografía}

1. Jeffreys AJ, Wilson V, Thein SL. Individual-specific 'fingerprints' of human DNA. Nature. 1985;314:67-73.

2. Carracedo A, Sobrino B, Lareu MV. Forensic DNA typing technologies:a review. En: Bogusz MJ (ed). Handbook of Analytical Separations. 2008;VI:9451000.

3. Gill P, Fereday L, Morling N, Schneider PM. The evoIution of DNA databases-recommendations for new European STR loci. Forensic Sci Int. 2006;156:242-4.

4. Butler JM, Shen Y, McCord BR. The development of reduced size STR amplicons as tools for analysis of degraded DNA. J Forensic Sci. 2003;48: 1054-64.

5. Roewer L, Krawczak M, Willuweit S, Nagy M, Alves C, Amorim A, et al. Online reference database of European Y-chromosomal short tandem repeat (STR) haplotypes. Forensic Sci Int. 2001;118:106-13.

6. Parson W, Dür A. EMPOP-a forensic mtDNA database. Forensic Sci Int. 2007;1:88-92.

7. Musgrave-Brown E, Ballard D, Balogh K, Bender K, Berger B, Bogus M, et al. Syndercombe Court. Forensic validation of the SNPforlD 52-plex assay. Forensic Sci Int Genet. 2007;1:186-90.

8. Phillips C, Fondevila M, García-Magariños M, Rodriguez A, Salas A, Carracedo A, et al. Resolving relationship tests that show ambiguous STR results using autosomal SNPs as supplementary markers. Forensic Sci Int Genet. 2008;2:198-204.
El siglo XXI nos traerá, como el siglo XX nos trajo la especialización de la medicina legal, una integración cada vez mayor de las subespecialidades. En este sentido, la genética ya es una pieza clave en el diagnóstico de la muerte súbita de origen cardíaco y la toxicogenética está cobrando una importancia ya imparable. Este hecho da más sentido todavía a la unión de la patología, toxicología y genética forense en estructuras organizativas donde los profesionales puedan interrelacionar.

9. Phillips C, Prieto L, Fondevila M, Salas A, GómezTato A, Alvarez-Dios J, et al. Ancestry analysis in the 11-M Madrid bomb attack investigation. PLoS One. 2009;11;4(8):e6583.

10. Brión M, Sanchez JJ, Balogh K, Thacker C, BlancoVerea A, Børsting C, et al. Introduction of an single nucleodite polymorphism-based "Major Y-chromosome haplogroup typing kit" suitable for predicting the geographical origin of male lineages. N. Morling. Electrophoresis. 2005;26:4411-20.

11. Brandstätter A, Salas A, Niederstätter $H$, Gassner C, Carracedo A, Parson W.Dissection of mitochondrial superhaplogroup $\mathrm{H}$ using coding region SNPs. Electrophoresis 2006;27:2541-50.

12. Phillips C, Salas A, Sánchez JJ, Fondevila M, Gómez-Tato A, Alvarez-Dios J, et al. Inferring ancestral origin using a single multiplex assay of ancestryinformative marker SNPs. Forensic Sci. Int. Genet. 2007; $1: 273-80$

13. Kayser M, Schneider PM. DNA-based prediction of human externally visible characteristics in forensics: motivations, scientific challenges, and ethical considerations. Forensic Sci. Int. Genet. 2009;3:154-61.

14. Xue $Y$, Tyler-Smith $C$. The hare and the tortoise: One small step for four SNPs, one giant leap for SNPkind. Forensic Sci. Int. Genet. 2010;4:59-61.

15. McCaughan F, Dear PH. Single-molecule genomics. J Pathol. 2010;220:297-306.

16. Observatorio de Bioetica y Derecho. Documento sobre pruebas genéticas de filiación, 2006. Disponible en: http://hdl.handle.net/2072/9108.

17. Editorial. Science in Court. Nature, 2010; 464(7287):325 . 